\title{
A KICKSTART $九$ LIFE: AUSTRALIAN FOOTBALL LEAGUE as MEDIUM for PROMOTING LIFESKILLS in CAPE YORK INDIGENOUS COMMUNITIES
}

\section{MAREE DINANTHOMPSON 1 , JUANITA SELLWOOD ${ }^{1}$ \& FELICITY CARLESS ${ }^{2}$}

1 School of Education, James Cook University, Townsville, Queensland, 4811, Australia

2 Health Promotion Unit, Tropical Population Health Cairns Network, Queensland Health, Queensland, 4870 , Australia

\section{Abstract}

This paper presents evidence collected from an evaluatory study of the Kickstart program conducted by Australian Football League (AFL) Cape York in far North Queensland. The aim of the study was to investigate the effectiveness of the Kickstart program in meeting its overall objective of enhancing lifeskills of Indigenous Australians through participation in AFL. Evidence collected via interviews with Indigenous youth, parents, teachers and Kickstart stakeholders (including community representatives) suggest mixed meanings surrounding the interpretation of "lifeskills", and yet improvement in the education, attitudes and lifestyle choices of Indigenous youth in the selected Cape York communities.
Introduction

Over a 12 month period across 2004-2005, an evaluation of the Kickstart program was undertaken by the School of Education, James Cook University, and Health Promotion, Tropical Population Health Unit - Cairns, Queensland Health. Underpinning the study was the overall aim of the Australian Football League Kickstart program which was, to not only increase participation in AFL but also "educate, assist and improve the attitudes and lifestyle choices of youth in remote communities" (Walker \& Oxenham, 2001, p. 5). Kickstart, as operated by AFL Cape York, consisted of the Auskick program lead by Regional Development Officers (RDOs), representative selection into the Kickstart Crusader teams and the abidance of the following selection guidelines:

- Attend school at least 3 days per week,

- Have no recent history of substance abuse (petrol sniffing, alcohol, smoking) or other drug history,

- No recent history with bullying or domestic violence within the community and school in which they are immediately responsible, and

- Be involved in the AFL Auskick program (Australian Football League Queensland, 2000).

The AFL Auskick program provided the basis for participation. Similar to the Auskick programs operating in metropolitan schools, it grants opportunity for the development of AFL skills and is the basis for the intra and inter-community competition. The aim of the Auskick program is to increase participation in sport through the AFL game (Australian Football League Queensland, 2000). The Kickstart program provides a representative developmental pathway for students (male to 16 years and female to 13 years) who wish to excel in the AFL game. However, to comply with selection into the Kickstart Crusader representative teams, students must obey the guidelines stated above. These are monitored by RDOs in association with schools and police. The added intent of these guidelines is to develop lifeskills that will improve attitudes and lifestyle choices. Further, Australian 
Football League Queensland (AFLQ, 2000) proposed Crusader program elements to frame the activities and operations. They included:

1. Meaningful and consistent community-based development of the game of AFL in which the children feel safe and secure.

2. Promoting a sense of pride and belonging when children represent their communities at intercommunity competitions and regional events

3. Developing raised self-esteem and responsibilities in children as they develop as role models for their communities.

4. Developing a culture in which children are not afraid to take risks in an attempt to achieve success.

5. Continually challenging children to extend themselves to improve on things they have already achieved.

6. Developing independence and lifeskills within secure and then gradually more challenging environments.

In Cape York communities, these elements provide the guidelines for relationships with stakeholders, such as Queensland Health, Queensland Police, Apunipima Cape York Health Council and the Queensland Cancer Fund. These stakeholders are invited to deliver workshops to students on various health issues with the view that the children share the information with their communities. AFL. Cape York coined this arrangement with stakeholders "reciprocal partnerships". They believe that their experience is in sport (AFL) and they support and promote the stakeholders product or message. This was achieved through promotion of logos, handing out information at school visits by RDOs, combined school clinics and workshops, and signage on AFL jumpers. In return, stakeholders ran professional development sessions, workshops for students and promoted and supported the work of AFL Cape York.

The focus for this paper is not on the total effectiveness of the Kickstart program in Cape York communities, but rather the interpretation of "lifeskills" and successful achievement or demonstration of lifeskills as told by students, parents, teachers and stakeholders.

\section{Literature informing the study}

The nomenclature of lifeskills, notions of health promotion in sport and recreational settings, links between communities and physical activity and education and physical activity, are relevant to the investigation of the Kickstart program.

\section{Current perspectives of "lifeskills"}

It is apparent that a naming debate surrounds the term "lifeskills". For the purposes of this study, the Kickstart program emphasises the enhancement of lifeskills for Indigenous youth through their participation in Auskick and Kickstart programs. For AFL Cape York, lifeskills have been linked to school attendance, no substance abuse and no violence (home, school, community). Other agencies present differing definitions of lifeskills.

The World Health Organisation (WHO) defines lifeskills as "abilities for adaptive and positive behaviour that enable individuals to deal effectively with the demands and challenges of everyday life" (WHO, 1993). They consist of personal, interpersonal, cognitive and physical skills such as decision making and problem solving skills, communication skills, coping with emotions and managing stress. Lifeskills, defined above by WHO are "fundamental building blocks for the development of personal skills for bealth promotion" and is one of the key action areas in the Ottawa Charter (WHO, 1998, p. 15).

The Queensland School Curriculum Council (QSCC) (2001) identify "lifeskills" as an "integrative element" across core curriculum in Years 1 to 10 (all Key Learning Areas). The QSCC definition is founded on the belief that there are (at least) four life roles that are interrelated and interdependent:

- Growing and developing as an individual;

- Living and relating to other people;

- Managing resources; and,

- Receiving from and contributing to local, state, national and global communities.

To be able to participate in these life roles, lifeskills must be developed. QSCC (2001, p. 4) state that "the word 'skill' is used in this context to encompass knowledge, practical performance, attitudes, beliefs, and values". At least four sets of lifeskills are identified:

- Personal development skills - such as, maintaining personal health and wellbeing; developing attitudes of perseverance, flexibility and adaptability; achieving high standards of self-discipline, personal conduct and social responsibility.

- Social skills - such as, working cooperatively with other people, and developing positive or pacifist strategies for cooperation and conflict resolution; acting ethically by recognising and respecting the rights, needs and viewpoints of others.

- Self-management skills - such as, setting personal goals and devising strategies to attain them; setting and maintaining priorities; using public services.

- Citizenship skills - such as, identifying, critically reflecting on and managing laws which govern personal, family, community and workplace activities; knowing how to respond in emergency situations.

Performance in each of these lifeskills can take place in varied contexts (family, community, educational, 
recreational, vocational) and consist of both practical and reflective elements (QSCC, 2001, pp. 4-9).

From another perspective, Education Queensland (EQ) have identified "lifeskills" as components of studying ethics and through supplementary programs, such as "Life's a Ball". Each of these interpretations brings new messages about lifeskills:

- In 1996, Education Queensland published a document that provided ideas for studying "ethics" in classrooms. In this document lifeskills encompassed such areas as human relationships education, active and informed citizenship, ethics and religious education (Education Queensland, 1996, p. 129).

- Life's a Ball is a supplementary program sponsored by the Commonwealth Bank. EQ has created a "lifeskills" link to this program. The program involves around one hundred of Australia's elite athletes who visit schools helping young people "improve their lifeskills and deal with difficult times in their lives" (Life's a Ball, 2001, para. 1). Areas of focus include communication, self-esteem, dealing with frustration, choices and consequences, setting and achieving goals, and overcoming bullying.

An additional slant is created by Queensland Health whereby lifeskills appears to have a direct link to mental health and in particular resiliency (Queensland Health, 2004). Further, New Zealand academics have created physical activity-based Lifeskills programmes (Hodge et al., 1999). These programs encompass skill-based workshops that target goal setting and achievement, development of sport skills, teaching responsibility through physical activity, experiential and adventure learning, self-esteem and self-worth. On the other hand, Botvin (2003) from United States of America, has established a program titled "Lifeskills Training" to specifically target misuse of smoking and alcohol in children. It is implemented across several States in America. The program teaches substance use resistance skills, normative education, personal selfmanagement skills and general social skills.

Definitions stated above display broad and narrow interpretations of "lifeskills". In addition, some take an informative position whilst others are preventative. However the majority of the definitions place a strong emphasis on the development of particular values, roles and skills that prepare people for their role in society. Interestingly though only AFL Cape York create a specific link to school attendance. It is apparent in this case that the particular contextual features of persons targeted have shaped this application.

\section{Promoting bealth in sport and recreation settings}

Sporting and recreation settings have been identified as providing excellent opportunities for the delivery of health programs. Participation in sport has been shown to have positive health consequences. Studies have shown greater milk and fruit consumption; lower rates of tobacco use, binge drinking, marijuana use and truancy; higher reported levels of self esteem: and lower levels of sadness, anxiety and suicidal behaviour in students who participate in school sports (Harrison \& Narayan, 2003).

The World Health Organisation (WHO, 2003) states that engagement in play and sports gives children opportunities for social interaction and integration as well as for learning the spirit of solidarity and fair play and can foster the adoption of other healthy behaviours. Sporting settings can encourage appropriate behaviours by providing opportunities for education and access to role models (Moodie \& Hulme, 2004). They can encourage health-enhancing choices such as eating healthy foods, discourage health-compromising behaviours such as smoking, and encourage healthy behaviours such as sun-smart practices (National Health \& Medical Research Council, 1996). Research shows that these issues are as relevant to spectators as participants in sport (Clarkson et al., 1999) and that introducing health-enhancing policies in sporting settings directly influences behaviour change (Donovan et al., 1999).

\section{Community and physical activity}

There is much evidence to suggest that community solidity and physical activity are inextricably linked. Studies conducted by Cameron and MacDougal (2000) in remote communities of the Anangu-Pitjantjatjara lands ascertained that during sporting carnivals many local people noticed a significant reduction of petrol sniffing, heavy drinking and juvenile offending. Beneforti and Cunningham (2002, p. 12) reinforce this potential when they contend that physical activity not only influences behaviours and characteristics of individuals, but that "the effects are likely to flow on to the community as a whole".

Messages of healthy lifestyles reaching the wider community are often inadvertently delivered by the young children that participate in sporting programs. Walker and Oxenham (2001, p. 40) reveal "the young ones [are] talking in language to their parents about the effects of alcohol and smoking", after their involvement with sporting programs.

Adams (2003) in addressing the needs of Indigenous Australian communities at the National Rural Health Conference highlighted the requirement for a holistic approach, which recognises the interconnectedness between, family and community. Strategies in providing policy, services and programs to the communities emphasise "it is about capacity building at the community level [to deliver the services] according to community needs and circumstances" (Adams, 2003, p. 2). Therefore, if a partnership approach is to occur, 
the implementation of physical activity and sporting programs will need to consider aims that are "inclusive of diverse spirituality, political beliefs, economic status, sexualities and lifestyles" as well as specific input from the Indigenous people in the communities (Adams, 2003 , p. 2). These factors and the involvement of local Indigenous people may also be a consideration for long term sustainability of physical activity and sporting programs in remote communities.

Community contribution could also take on the form of involvement in assisting with organisation of carnivals, coaching, helping with training sessions, umpiring games, taking part in administration, ensuring maintenance and monitoring of equipment and resources. Contribution to sporting programs from community members in this regard has been highlighted by Beneforti and Cunningham (2002, p. 12) to enhance community cohesion through the opportunity to develop skills, self-esteem and a sense of purpose. They also suggest that the main indicators to the success of sporting programs in communities involve their support through community ownership and control, planning and delivery, a holistic approach, and links to partnerships with the programs and agencies (Beneforti \& Cunningham, 2002, p. 13).

Further, Tatz (1995, p. 357) suggests in the Toomelah Report that "sport is the major thing that holds the community together". Therefore, sport can be a major factor in generating reciprocal partnerships between schools and communities as it is the social force that brings these together. This idea is reiterated by Cameron and MacDougal (2000, p. 1) who suggest that sporting programs in Aboriginal communities "act as catalysts for social and traditional cohesion". As a result, participation in sport and physical activity can provide a sense of belonging, loyalty and support for young people. Gowell (2000, p. 1) proposes that "for many Indigenous people sport provides opportunities for positive life experiences ... and a way out of difficult social situations". This view is also reinforced by Cameron and MacDougal (2000, p. 2) who suggest sport and physical activity have the potential to improve "quality of life ... and allows one to escape from day-to-day reality of family conflict, homelessness, or the temptations to use alcohol, drugs or inhale petrol."

Essentially, sport and physical activity remain a part of Australian culture that involves relationships and certain forms of conduct between players and audience (Wright, 1999). These relationships expose the complexities of socialisation of various groups in sport, but they also foster opportunities for the development of loyalty, discipline, feelings of belonging and support. Clearly, physical activity (including sport) provides an arena for Indigenous Australian children to engage encouragingly in the community.

\section{Education and physical activity}

Education is strongly linked to improved health and to the future of generations. It is common practice for preventative health education programs to be implemented across Australia in Indigenous and nonIndigenous contexts that focus on the enhancement of personal skills and supportive environments. The Cape York Justice Study (Queensland Government, Department of Communities, 2001) identifies education as central to improving opportunities for Indigenous youth.

Further, specific initiatives and strategies that link education and physical activity have been created for Indigenous youth. Of most concern in Indigenous communities is the attendance rates of the Aboriginal and Torres Strait Islander population in schools. In general, attendance rates for Indigenous students are significantly lower than all Queensland rates, and continue to fall as age increases. In particular, transition from Year 7 to 8 and 8 to $10(\mathrm{EQ}, 2003 \mathrm{~b})$ are noted as areas of fallout. In response to this situation in Queensland, EQ has created such initiatives as "Partners for Success" and "Aboriginal and Torres Strait Islander Career Aspirations Pathways Program (AICAPP)". The Partners for Success Action Plan 20032005 (EQ, 2003a) has identified attendance, retention and completion; and literacy attainment as priority action areas and targets. AICAPP focuses on transition from Year 10 to Year 11 and 12 with a particular emphasis on creating career pathways for Indigenous youth. In an AICAPP study in 2002, it was reported that Health and Physical Education was the most preferred subject for Indigenous boys and second most preferred for Indigenous girls (EQ, 2000). Further, the most preferred career area was Health, Sport and Community Services with $28 \%$ of respondents.

- Specific to improving attendance rates, physical activity has been utilised as a method to encourage students to attend school. Lehmann et al. (2002) investigated the "no school, no pool" initiative in Western Australia aimed at increasing and maintaining school attendance. This strategy has been applied in the Northern Territory. However, Beneforti and Cunningham (2002) suggest that measuring school attendance can be difficult if relying on only one record per day due to students leaving school grounds during the day.

Physical activities, in this case in the form of recreational programs, have been cited as being useful in the primary intervention of petrol sniffing in Australian communities (d'Abbs \& McLean, 2004). Nonetheless their effectiveness relies on sensitivity to the needs of the community. Other factors include the provision of a range of programs, experiences that are engaging and exciting and provide opportunity for risk-taking, provision of opportunities for both sexes, availability after hours and weekends, and targeting youth populations (d'Abbs \& McLean, 2004, p. 34). 
In Chicago, United States of America, Hellison (1995) has developed programs that focus on enhancing social and self-responsibility through participation in physical activity. Central to the program is Hellison's belief that "physical activity can act as a powerful vehicle to help kids with their personal and social-moral lives outside the physical activity setting" (Hellison, 2000a, p. 4). He specifically targets what he calls underserved youth. The framework identifies five levels of responsibility: respecting the rights and feelings of others; participation and effort; self-direction; caring; and application outside physical activity (Hellison, 1995). It requires participants to set goals to improve autonomy and control in dealing with day-to-day challenges. Martinek and Hellison (1998, p. 47) state: "alternative physical activity programs for underserved youth have used goal-setting to help children overcome poor decisionmaking, increase social competence, and become optimistic". Martinek and Hellison also acknowledge that achieving goals may not be possible due to the dysfunctional communities these youth live in.

Beneforti and Cunningham purport that "the salience of sport may attract pupils to educational programs" (2002, p. 11). An innovative program in Victoria has applied this notion. Associate Professor Richard James from University of Melbourne has joined with the Rumbalara Football Netball Club in the Goulburn Valley, Victoria, to establish the Academy of Sport, Health and Education (ASHE). James (University of Melbourne, 2003, para. 1) states: "ASHE will be a unique educational institution for Victoria in the use of studies in sport to engage young Indigenous people in education and training" and "central to this concept is the commitment of Indigenous youth to sport and the passion for sport in the Indigenous community". In 2004, the Certificate II in Sport was introduced to help address dropout rates among Indigenous teens. Andy Cowan (University of Melbourne, 2004, para. 8), ASHE's program coordinator states: "Using a sportbased curriculum, the Certificate II in Sport focuses on health, lifeskills and general education". These include personal development, leadership, computers, literacy and numeracy. More recently, the Department of Education, Science and Training (DEST) instigated the development of The Sporting Chance Programme. These school-based sports academies across Australia will use sport programmes to increase the level of engagement of Indigenous children and young people in schooling and improve their educational (DEST, 2007).

Whilst physical activity has been linked to educational outcomes, Olsen et al. (2002) suggest the need for cultural adjustments to educational environments to encourage Aboriginal and Torres Strait Islander participation. Such adjustments include: limit direct eye contact as it is disrespectful for Aboriginal and Torres Strait Islander students, consider exposure of the body as it can cause conflict, singling out is of great embarrassment, and family structures are usually extended and require different understandings by teachers. Blitner et al. (2000, p. 30) propose a set of pedagogical principles for teachers of Aboriginal and Torres Strait Islander students which promote cooperative rather than competitive learning environments and that "Aboriginal and Torres Strait Islander teaching and learning is continuous throughout our lifetime, starting from birth and ceasing when we [Aboriginal and Torres Strait Islander people] pass away". Hence, a focus on lifelong learning is promoted.

The review of literature provided lenses to inform the research methods of the evaluatory study and identify and analyse the aims and intentions of the Kickstart program via the activities and collated data.

\section{The study}

Methods chosen reflect a sociological account of factors within the Kickstart program as it was concerned with how the participant (student, parent, teacher, stakeholder) perceives it (Burns, 2000). Data collection, selection of participants, interviews and data analysis is explained in the following sections.

\section{Data collection process}

This evaluatory study used document analysis and interviewing as the main data collection methods. Document analysis included AFL Cape York Kickstart program information such as brochures, parent and student booklets/letters, role descriptions of regional development officers, program initiatives and records of participation numbers. In addition to these were documents supplied by stakeholders specific to the Kickstart program.

Focus group interviews were considered most appropriate in this case study as a large proportion of the participants were school students. In order to accommodate the students, group interviews were considered to be less intimidating than individual interviews. Furthermore, group interviews have the capacity to bring together various opinions and a wide range of perspectives (Cohen et al., 2000).

The interviews were conducted face-to-face in a semi-structured format (Burns, 2000). This format was used to allow for flexibility of the interview to resemble conversations, pursuing the interests of both the researcher and respondent. Although the questions were pre-established the aim was to leave the process open enough to allow the interviewee to direct the flow. Therefore, questions were not followed in order but flowed from the response of the interviewee. In this process the interviewer became both facilitator and moderator. The formulation of research questions came directly from the literature review conducted in this evaluation. 


\section{Sample}

Four schools in the rural/remote area of Cape York were selected by AFL Cape York as the sample for this evaluation: Weipa, Mapoon, Aurukun, and Napranum. Purposive sampling has been applied to seek out the groups, settings and individuals "where the processes being studied are most likely to occur" (Denzin \& Lincoln, 1998 , p. xiv). The Western Cape communities had the longest involvement in the Kickstart program, hence the desire to sample in that region. The research team visited the four schools over the course of four days and conducted interviews with students, teachers, parents and other key stakeholders. Additional stakeholder interviews were conducted outside of this timeframe.

\section{Case site descriptions}

Weipa is located in the Gulf of Carpentaria and is the main port for the region as well as providing services for the surrounding Aboriginal communities which are the other three case sites included in the study. Weipa has a population of approximately 4000 people. It is also a large Bauxite mining area with a large Aboriginal population. Weipa has education facilities to Year 12 and has approximately 600 students. A community campus has commenced operation (Queensland Government, 2003).

Mapoon is a small Aboriginal community in far North Queensland, just north of Weipa. Napranum is situated approximately 960 kilometres north west of Cairns, with the last stretch consisting of an all year access road, a distance of 86 kilometres from Weipa on the Gulf of Carpentaria. In the last census around 197 people were counted; about 92 per cent of the total population are Aboriginal or Torres Strait Islander (Queensland Government, 2003). Mapoon has educational facilities to Year 7.

The shire of Aurukun covers an area of 7,500 square kilometres and is situated about two-thirds of the way up the western side of Cape York Peninsula. Aurukun has a population of approximately 1,084 , as of June 2001 (Queensland Government, 2003). Aurukun has educational facilities to Year 7.

Napranum is approximately 700 kilometres from Cairns. The community has a population of approximately 789 , as of June 2001, with about 95 per cent of the total population being of Aboriginal or Torres Strait Islander origin (Queensland Government, 2003). Napranum has educational facilities to Year 7.

\section{Participants}

The samples of students were chosen from the following age groups, under 12's (U12), under 14's (U14) and under 16's (U16). These groups are also the AFL representative age groupings. Wherever possible, both male and female participants were included in the groups. In addition, other factors for selection included participation in the Crusader Representative level of the Kickstart program, participation in Auskick (the AFL skill offered program) or no participation in either of these. The purpose in choosing such a varied sample of students was to counteract any bias and therefore produce a diverse range of responses.

Students were asked about the types of physical activity they engage with in general. Questioning then went on to focus in the Auskick and Crusader programs both of which fall under the umbrella of Kickstart. The selection guidelines were a strong point of the study as they are part of the criteria to sustain membership in the crusader team. The selection guidelines were linked to the concept of lifeskills and their understanding of the term.

In each community visited, teachers, parents of the students involved in the program and other stakeholders that offer funding, were interviewed about their involvement with the program. Teachers and parents were key to the sustainability of the Kickstart program in the communities. Questions focused on their role in the Kickstart program and any positive or negative experiences they have encountered. These participants were asked to extend their views on the possible effects on the school culture and community as a whole. Parallel to the student's questions the adult group were asked about the selection guidelines and their relation to lifeskills.

Tables 1 and 2 outline the sample of interviewees. External feedback was preferred by AFL Cape York hence Kickstart staff were not interviewed.

Table 1: AFL Kickstart interviews conducted with site participants.

\begin{tabular}{|l|c|c|c|c|}
\hline \multirow{2}{*}{ Site } & \multicolumn{3}{|c|}{ Number of people interviewed in each site } \\
\cline { 2 - 5 } & $\begin{array}{c}\text { Students } \\
\text { U12/U14/U16 }\end{array}$ & Parents & Teachers & TOTAL \\
\hline Weipa & 18 & 2 & 3 & 23 \\
\hline Aurukun & 9 & 1 & 4 & 14 \\
\hline Mapoon & 8 & 0 & 2 & 10 \\
\hline Napranum & 3 & 0 & 3 & 6 \\
\hline TO'TAL & 38 & 3 & 12 & 53 \\
\hline
\end{tabular}




\section{Analysis of data}

Content analysis was used to identify the themes, main concepts and meanings (Burns, 2000). The data was classified into common themes on particular issues that became prominent and consistent throughout the evaluation (Spradley, 1979). To improve internal validity and supplement the richness of data, triangulation (Burns, 2000) was used in the analysis of various participants' perceptions of the Kickstart program, document analysis data and relevant literature.

Confidentiality of data is of utmost importance in this study complying with James Cook University ethics procedures. All data has been coded (for example, Student a, Parent b) and some quotations have been re-written to respect the anonymity of participants (without loss of meaning). In the case where participants used names within the interviews, [name deleted] has been inserted to comply with anonymity.

\section{Limitations of the study}

Community visits were limited to a four-day period across Cape York. Although common themes were evident in data analysis themes, this cannot be considered symbolic of all Indigenous communities in Cape York. The time spent in communities was brief and may have had an adverse effect on the number of interviewees. Data is specific to the four case sites and may be limited in perspective. Subsequently, the researchers have refrained from delivering statements of generalisations across the board to similar programs.

I Interpretations of lifeskills

For AFL Cape York, lifeskills has been linked to school attendance, no substance abuse and no violence (home, school, community). The analysis of lifeskills includes the understanding of the term by participants (students, parents, teachers and stakeholders) and an understanding of the messages portrayed in the selection guidelines.

\section{Understandings of lifeskills}

The convoluted nature of the term "lifeskills" identified in the literature review was highlighted in the data.
Interpretations brought both common understandings and convoluted messages about lifeskills. Student data demonstrated some understanding of the conceptual nature of "lifeskills". The students' comments are generic however and show limited understanding of the term as they are unable to voice specific behaviours and skills as being part of lifeskills; such as self-management skills. However, there is evidence of development of skills and values, such as respect. Conversely, it could be interpreted that the students are following someone else's rules:

Look after your life (Student c).

... how to be a healthy and fit man (Student a).

Getting along; respecting (Student e).

People being nice to each other (Student a).

I follow those rules; Looking after your life (Student d).

These behaviours could be interpreted as achieving self-discipline, showing personal conduct and social responsibility, all of which are identified by QSCC (2001) as elements of "lifeskills". Furthermore, WHO (1998) identifies adaptive and positive behaviours that respond to demands and challenges of everyday life as elements of "lifeskills". The student comments suggest that they have developed positive behaviours to deal effectively with community contexts. The data suggests that AFL Cape York's mission statement "to enhance the lifeskills of Indigenous Australians" is being achieved, although the terminology of "lifeskills" was a "hidden" message for the students in the Kickstart program in the case sites studied.

Teachers and parents were more familiar with the terminology, as were some of the stakeholders. However, mixed interpretations were presented, ranging from an emphasis on communication and social skills to resiliency. This was highlighted as important not only for Indigenous students (as the mission statement might indicate).

Parents in particular highlighted the need to develop social skills whereas teachers extended the term to include health behaviours:

Table 2: AFL Kickstart interviews conducted with stakeholders.

\begin{tabular}{|l|c|}
\hline \multicolumn{1}{c|}{ Stakeholder } & No of participants \\
\hline Queensland Health & 2 \\
\hline Queensland Police & 1 \\
\hline Tropical Institute of TAFE Queensland & 1 \\
\hline Sport and Recreation Queensland & 1 \\
\hline Western Cape Consultative Committee - Chairperson & 1 \\
\hline Alcohol Education and Rehabilitation Foundation Ltd. & 1 \\
\hline TOTAL & 7 \\
\hline
\end{tabular}


Lifeskills ... would be like learning to get along with other people in a social environment ... trying to find ways of sorting out differences within themselves, that they can achieve (Parent b).

... lifeskills has got a pretty broad base for me ... a whole range [including] nutrition (Teacher b).

For stakeholders, understanding was much broader to suggest a balancing of the whole of life. Extended interpretations have been evidence with links made to education, literacy and numeracy, health, the law, and family and community:

[Lifeskills include] the balancing of physical activity, within their whole improvement of life, looking at their quality of life based on nutrition, based on healthy living, based on moral standards ... even the law, basing it within the law and how sport, in particularly AFL in this case can encourage participants to be mindful of the community law and also state law I suppose (Stakeholder f).

[Lifeskills are] going to school, being educated, gaining confidence $\ldots$ be able to read and write ...ball skills and with their networking, and being in a team ... I think that is really important that they be given that (Stakeholder d).

This is all good stuff [walk away, cool down; say no to drugs]. And it is not just Indigenous kids, it is all kids really ... what they are doing is all about values and you can't stress those sort of things enough to kids and show them the example. You certainly can't tell them ... show them ... develop them enough in those areas ... (Stakeholder b).

I guess the bottom line is that you are giving people information that they can actually make informed choices. You show them what a good choice is, getting them to identify for themselves (Stakeholder c).

Comments illuminate the complexity of the term "lifeskills" and, overall, data has reiterated the mixed messages in defining "lifeskills". Danish (2002, p. 53) suggests that "programs [to teach lifeskills] need to be sensitive to developmental, environmental, an individual differences and to the possibility that the needed lifeskills may not be the same for individuals of different ages, ethnic, and/or racial groups, or economic status". What is apparent however, is that there is evidence of the development of "lifeskills" (in the broader sense of the word) in the Kickstart program, though partial in nature.
Selection guideline messages

Physical activity has been promoted in research (WHO, 2003; Lehmann et al., 2002; Beneforti \& Cunningham, 2002) as a strategy for intervention in improving educational outcomes (largely through attendance at school) and the promotion of social values and moral development (Hellison, 1995).

\section{Scbool attendance}

Students were able to make a direct link between school attendance, learning and keeping healthy. Parents and teachers were supportive of the strategy and linked the Crusader program to an improvement in school attendance:

Do well at school ... you have to come to school instead of staying home ... trying to keep healthy. Well, ever since it started, a lot of kids have been doing a bit better at school ... sometimes when you are not that activated, you don't do - you have got to eat well, so if you eat the wrong food in the morning, you will be tired at school (Student c).

... attendance ... that is really good what they are trying to teach the kids. The attendance, responsibilities ... and then they see if they muck up school or if they muck up at home it gets reported to school. So they know it gets back to Rick Hanlon (RDO) and then they get out of the Crusaders Cup which is what they don't want (Parent b).

... attendance was the easiest thing to see ... the Kickstart program was ... part of a broad range of initiatives ... which lead to much greater attendance ... and [school] ended up with $90 \%$ attendance ... Kickstart formed a fairly big cog in that wheel (Teacher b).

Interpretations of these comments suggest that direct links to education outcomes, specifically school attendance, is not only evidenced from the Kickstart Crusader program.

Education Queensland (2003b) has identified the transition from Year 7 to 8 and 8 to 10 as times when attendance rates for Aboriginal and Torres Strait Islander students is low. As such, there are many programs that focus on transition (see Education Queensland, 2003a, 2003b, Partners for Success). Comments from the teachers suggest that Kickstart is an effective vehicle for supporting students during that period and may link to educational outcomes through higher attendance: 
... because Western Cape College is made up of four campuses ... when the kids all come together in year seven ... they know each other ... [playing AFL] really helps them to fit into our school life here. So it's not just a coming together of kids that don't know each other, they have often had those relationships that have been built through sport (Teacher a).

... the school usually lists one of the transition [factors] is the AFL ... and a successful transition too...when the going gets tougher, and trying to mix in, I just reckon it makes it so much easier for them. It assists them anyway (Teacher a).

Data generated suggests limited integration and educational gain between Kickstart and the school curriculum. Some attempts were made although links to the curriculum were informal:

... in my situation we are working through a personal health plan [Year 6 curriculum] ... nearly all of them are playing AFL and they have quite a strong focus on football as part of their health plan ... what we talked about and it is completely in line with what is happening with the Kickstart program (Teacher $f$ ).

... the kids come in ... and they chat about their Kickstart and we are doing a health program at the moment and they can tell you about "Oh we run around at Kickstart, that is always good for us" so [we] related their activities in Kickstart back to their healthy way of life and the food we eat ... (Teacher e).

The focus on education outcomes remains at the surface level by targeting school attendance. Further, the Kickstart program is seasonal and only requires three-day attendance per week, in contrast to EQ policy that adheres to "schooling" legislation which states that a child must attend school on every school day for the educational program in which the child is enrolled (Queensland Government, 2003, p. 97). Recent research in Queensland schools (Luke et al., 1999) suggests that stronger connections be made between in and out of school activities, providing a link to the real world. They title this "connectedness". It is apparent that there are possibilities of stronger connections to be made to the Cape Curriculum (EQ, 2003b). Kickstart would form a real life context for rich learning experiences for both boys and girls. This would lead to a deepening of education outcomes with an extension to literacy and numeracy development. Furthermore, an extension of educational outcomes could be pursued similar to that of the ASHE in Victoria whereby Indigenous youth enrol in a Certificate II in Sport that focuses on health, lifeskills and general education (University of Melbourne, 2004).

\section{Social and moral development}

Along with school attendance was a focus on social and moral development via the guidelines stating "no recent history of substance abuse (petrol sniffing, alcohol, smoking) or other drug history, and no recent history with bullying or domestic violence within the community and school in which they are immediately responsible" (Australian Football League Queensland, 2000 , p. 2). Analysis of data suggests some degree of development of these skills.

Timperio et al. (2004) suggest that for adolescents, physical inactivity is associated with a range of healthrisk factors such as smoking and alcohol use. The Kickstart program, in its promotion of participation in physical activity and possible development of social and moral values, appeared to provide an avenue for students to make connections between the messages of no involvement in drugs to improved health and wellbeing:

No fighting, no drinking. No smoking dope. You got to be fit and healthy to be in a team (Student a).

No smoking, no drinking because if you smoke, you can't run and you can get dehydrated (Student e).

Like drug free. So no to drugs, it will ruin your body. To be able to stay fit (Student c).

This connection illuminates Shilton and Brown's (2004) statement that participation in physical activity leads to prevention of ill-health. Students also expressed the responsibility of managing their own emotions, and keeping out of trouble:

Walk away, cool down; Yes sometimes when we play soccer, walk away, cool down. Sometimes, we just go away. Just go and ask if we can play another game with them; No punching (Student a).

Tell someone; and cool down (Student e).

Indeed Kickstart appears to have brought about behaviour change through the participation in physical activity (Donovan et al., 1999) through the provision of a diversionary tactic that has reduced boredom and vulnerability, factors that demonstrate links to drug use and participation in violence.

Student responses suggest that the development of social and moral values in the minimisation of drug use and violence is at a surface level, similar to 
educational outcomes as a whole. There is limited extension of the messages to personal benefits as students made limited connection to benefits outside the Kickstart program. It must be noted however, that students were able to make connections to health and wellbeing in general and as the evaluation did focus on the Kickstart program specifically, it is difficult to state that students would not use this knowledge and skill personally, away from Kickstart. The development of the skills to say no to drugs and walk away from violence must be considered as part of developing lifeskills which may also benefit them outside the game.

\section{Crusader program elements}

Data was collected from participants either through direct comment on the AFL Cape York Crusader program elements or via other interview questions for evidence on the Crusader program meeting these elements (see Introduction section for element detail). Rather than take each element individually a clustering of the central components, including safety, risks and challenge; self-esteem, pride, responsibility and role models; and independence and lifeskills, have been utilised to analyse data.

Comments from students, parents, teachers and stakeholders demonstrate that the Kickstart program promotes risk taking in a safe and supportive environment that is challenging and rewarding. Kickstart has asked students to take risks in participating in AFL in a traditional rugby league environment and to confront social practices, such as drug use. At the same time, the program is continually challenging and rewarding to students who abide guidelines through the provision of the developmental pathway and scholarship opportunities. Comments below highlight these points:

... any of the games ... any of the activities that are operated are always conducted with the children's safety as paramount ... The Area Development Manager Rick is constantly training their staff in how to establish things correctly, how to run activities in a safe manner, matching up of players so there are not oversized and small size players and yeah, I think they do that quiet well (Stakeholder f).

Well certainly the game has developed in each community ... You see kids now playing AFL during their lunch breaks, six years ago it was just unheard of. So the game has certainly developed at a community level in which children feel safe and secure ... (Stakeholder e).

... certainly with the Crusader program and the AFL program, that there is that level they can aspire to (Stakeholder c).
... like just an outside perspective of what is out there, you know a big place. He didn't have the opportunity to go there before, but part of the AFL program it was like a big step out and he came back so excited (Teacher d).

However, one stakeholder saw that the risk-taking element was hidden or assumed in the operation of Kickstart, in particular the focus of risk taking for the students.

I think that is well promoted by the organisation, I haven't seen a huge amount of evidence to suggest that they actively promote kids to not to be afraid to take risks. I think it's probably indirectly assumed or encouraged (Stakeholder $\mathrm{f}$ ).

Data (including observations) also demonstrated that Kickstart has played a role in the development of self-esteem, pride, respect for others, community cohesion and promoting physical activity. Comments on self-esteem, confidence, respect and responsibility were prominent:

They [the students] became a lot more confident, a lot more skilful and became quiet proud of their achievements, so all those things. Particularly the confidence, the confidence to have a go and knowing they have the support to do it (Teacher b).

It is lifting the self-esteem a bit (Teacher a).

... Aboriginal kids ... [are] quite shy ... but when they get together in the course of a few days, you watch them come out of their shells ... they are starting to get confidence in themselves, confidence in the people, confidence in the program ... (Stakeholder b).

[the Kickstart program] ... shows them responsibility (Parent b).

It makes them more responsible in how they act ... (Teacher c).

... a couple of years ago I watched some of the games in Weipa, in which Aurukun was playing and there was a huge sense of pride that the kids were coached by one of the older kids where they used traditional language and they sort of were very much strong about their team, also the supporters that were there, supported the individual teams, so there is a great feeling of team support that flows on back to community support. And they probably do that very well (Stakeholder f). 
Comments also suggested personal growth in the students and in particular, maturity:

You see the kids develop. We saw in Weipa over the last couple of years, the kids who start off and don't really have much to say, and then by the end of the carnival over three days, have got something to say during the team talks and stuff like that, and take on responsibility so will actually will be the person who comes over with the school card. Or organises the boys to go for the run, to warm up and stuff like that (Stakeholder e).

My nephew, he has matured a lot ... and I have seen him physically change as well as mentally, maturity wise sort of thing (Parent b).

An additional comment recognises the risks associated with these responsibilities:

Absolutely, it is up to each kid to be responsible for their behaviour, to cooperate with what is happening, that is a challenge (Teacher $\mathrm{f}$ ).

The implementation of the Kickstart program in these communities appears to have increased levels of self-esteem and confidence, with possible links to decreased rates of drug use and truancy (Harrison \& Narayan, 2003).

Links were not made to the students being role models for other students or their community. Data generated only made a connection of role modelling to AFL Cape York staff:

... you have got people like Nick and Rick [AFL Cape York staff], they are really good role models as well (Parent b).

... I think that we shouldn't underestimate the people that are actually delivering the programs, how much of a role model that they are to these young people, in developing good relationships with the young people ... (Stakeholder c).

According to Moodie and Hulme (2004) access to role models in sporting settings is positive in providing opportunities for education, social interaction and integration.

Additionally, observations in each of the communities brought attention to the sense of pride students have in the wearing of their Kickstart representative travel uniforms in the school setting:

The boys ... girls as well ... when they are in their uniforms you can just see they are very very proud to be wearing the uniforms and they like their photos taken at every opportunity. And [they arel very keen to win, to beat the other regions as well, so certainly very proud (Stakeholder e).

Finally, the comments made on the development of independence and lifeskills identified in element six were likely to be most emphatic in the data:

... one of the most important components of the program is the independence ... like leaving their community and going away with groups of people who they don't always know (Stakeholder e)

This is all good stuff [walk away, cool down; say no to drugs]...I just think that what they are doing is all about values and you can't stress those sort of things enough to kids and show them the example. You certainly can't tell them ... show them ... develop them enough in those areas ... particularly up here in the Cape, where the social issues seem to be bigger than possibly anywhere else (Stakeholder b).

... what AFL is trying to do is engender in the kids an alternative to the lifestyle that some of them are leading ... coming from homes where they are drinking all the time ... where it is acceptable not to go to school ... by not accepting that and encouraging the kids not to go down that path... (Stakeholder d).

Overall, comments suggest that participation in the Kickstart program has been a medium for social and moral development. They provide evidence of skills, behaviours and responsibilities demonstrated in respecting rights and feelings of others, participation and effort, self-direction and caring, that were transferable outside of physical activity (Hellison, $1995,2000 \mathrm{~b})$. In this evaluation, comments suggest applications in the school and community:

[name deleted] has sort of matured. He is going to the under fourteens now and he is mature, he is responsible, he is dedicated to both school and AFL and other sports that he is undertaking (Parent b).

Giving some direction and focus outside of the classroom itself (Teacher a).

... and I also think it gives them, they make more friendships ... and they are able to mix better with kids, in, like outside of [town] (Teacher d).

An interesting comment was to emphasise the transfer of these values across genders and cultures: 
It is working across cultures and across genders too ... because you get black kids, white kids, boys, girls all on the same field, and it is not just play but it is then backed up in educating the kids before they play, stopping the game during the play, after the play (Teacher a).

On the other hand, a further comment suggests that the Kickstart program is seen as contributing to or reinforcing values and responsibilities, rather than being totally accountable.

I think it does, but I think it is really hard to say whether, like to me AFL is just part of a piece of a puzzle that we are all trying to work on together (Teacher a).

Nonetheless, Don Morris (2003, p. 62) contends that physical activity programs with social responsibility philosophies "promote positive change in overt actions by students". Whilst they tend to target "atrisk" or "underserved" youth, these programs are appropriate for all students in that they create an equal opportunity context, to develop and act on social skills and that there is an effect on school climate and school performance (Don Morris, 2003). In this evaluation, it is apparent that Kickstart is a values-based program that demonstrates evidence of achieving social and moral development for students.

\section{A kickstart to life: Concluding remarks}

This evaluatory study provided a rare opportunity to study a health promotion program for Indigenous youth in situ. The effectiveness of delivering health messages to youth through sport/physical activity programs in Cape York was investigated in practice. AFL Cape York has satisfied its mission statement of enhancing lifeskills of Indigenous Australians and increasing participation in sport through the AFL game. Data analysis demonstrated the positiveness of the Kickstart program implementation in the Cape York communities. Lifeskills of school attendance and social and moral development have been achieved, although at a surface level. Elements of self-esteem, risk-taking, success, pride, challenge and social cohesion have been attained. Gaps were identified in the mixed interpretations of lifeskills, and integration and educational gain in school curriculum. Kickstart has provided positive life experiences and a way out of difficult situations in their personal and community lives (Gowell, 2000). There is need for further research in the possibilities of physical activity as a medium for development of lifeskills with the intent of positive educational experiences and gain.
Acknowledgements

Monies granted from AFL Cape York, Tropical Population Health Cairns Network (Queensland Health) and School of Education, James Cook University enabled the research agenda for this project.

\section{References}

Adams, M. (2003). The national franework for improving the bealth and wellbeing of Aboriginal and Torres Strait Islander males: The draft framework. National Rural Healtb Conference, March 1-4 (pp. 1-5). Retrieved 19 August, 2004, from http://wwwabc.net.au/rural/ruralhealth2003/stories/s798366. htm

Australian Football League Queensland. (2000). AFL Kickstart. Brisbane, QLD: AFL Queensland.

Beneforti, M., \& Cunningham, J. (2002). Investigating indicators for measuring the health and social impact of sport and recreation programs in Indigenous communities. Casuarina, NT: Cooperative Research Centre for Aboriginal and Tropical Health.

Blitner, S., Dobson, V., Gibson, F., Martin, B., Oldfield, N., Oliver, R., Plamer, I. \& Riley, R. (2000). Strong voices. Batchelor, NT: Batchelor Institute of Indigenous Tertiary Education.

Botvin, G. J. (2003, 6 December). Substance abuse - school-based prevention program reduces smoking and alcohol use in children. Obesity, Fitness and Wellness Week, p. 29.

Burns, R. B. (2000). Introduction to research metbod (4th ed.). Melbourne, VIC: Addison Wesley Longman Australia

Cameron, M., \& MacDougall, C. (2000). Crime prevention through sport and physical activity. Trends and Issues in Crime and Criminal Justice, 165. Retrieved 20 August, 2004, from http://wwwaic.govau.

Clarkson, J., Donovan, R. J., Giles-Corti, B., Bulsara, M. \& Jalleh. G. (1999). Survey on Recreation and Health 1992-1998, Volume 1: Participation in Sport and Racing. Health Promotion Evaluation Unit. Department of Health and Graduate School of Management. Perth, WA: The University of Western Australia.

Cohen, L., Manion. L., \& Morrison, K. (2000). Research metbods in education (5th ed.). London: Routledge/Falmer.

d'Abbs, P. \& McLean, S. (2004). Petrol sniffing in Aboriginal communities In J. Healy (Ed.), Indigenous healtb: Issues in society (pp. 33-36). Sydney, NSW: Spinney Press.

Danish, S. (2002). Teaching life skills through sports. In M. Gatz, M. A Messner \& S. J. Ball-Rokeach (Eds.), Paradoxes of youth and sport (pp. 49-60). New York, NY: State University of New York Press.

Denzin, N. \& Lincoln, Y. (Eds.). (1998). Strategies of qualitative inquiry. Thousand Oaks, CA: Sage Publications.

Department of Education, Science and Training (DEST). (2007). The Sporting Chance Programme. Retrieved $30 \mathrm{March}$, 2007, from http://www.dest.gov. au/sectors/indigenous_education/programmes_funding/programme categories/sporting_chance_programme_school_based_sports_ academies/sporting_chance info.htm.

Don Morris, G. S. (2003) Social responsibility through physical activity. In A. Laker (Ed.), The future of physical education: Building a new pedagogy. New York, NY: Routledge. 
Donovan, R. J., Jalleh, G., Clarkson, J., \& Giles-Corti, B. (1999). Sponsorship Monitor Evaluation Results 1998/99. Health Promotion Evaluation Unit, Department of Health and Graduate School of Management. Perth, WA: The University of Western Australia.

Education Queensland (EQ). (1996). Resources for studying ethics in primary scbools. Brisbane, QLD: Queensland Government.

Education Queensland (EQ). (2003a). Partners for Success Action Plan 20032005: Executive summary. Brisbane, QLD: Queensland Government.

Education Queensland (EQ). (2003b). Partners for Success: Scbool Information Kit 2003-2005. Brisbane, QLD: Queensland Government.

Gowell, D. (2000). Playing the game: Is sport as good for race relations as we'd like to think? Aboriginal Studies 1E2, 12-19.

Harrison, P. A., \& Narayan, G. (2003). Differences in behaviour, psychological factors and environmental factors associated with participation in schools sports and other activities in adolescence. Joumal of School Health, 73(3), 113-120.

Hellison, D. (1995). Teacbing responsibility tbrough physical activity. Champaign, IL: Human Kinetics.

Hellison, D. (2000a). Teaching responsibility through physical activity: 'Experiments of one' in the 'swamp of practice'. Journal of Physical Education New Zealand, 33(3), 4-7.

Hellison, D. (2000b). Physical activity programs for underserved youth. ACHPER Healtby Lifestyles Joumal, $47(2), 15-17$.

Hodge, K., Cresswell, S., Sherburn, D., \& Dugdale, J. (1999). Physical activitybased Lifeskills programmes: Part II - example programmes. Journal of Physical Education New Zealand, 32(2), 12-15.

Lehmann, D., Silva, D., Tennant, M., McAullay, D. Johnston, J., \& Nannup, I. (2002). Impact of introduction of swimming pools on bealth of Aboriginal children and adolescents living in remote areas of Western Australia. Perth, WA: TVW Telethon Institute for Child Health Research.

Life's A Ball. (2001). Life's a ball. Retrieved 3 September, 2004, from www lifesaball.net.au/info.

Luke, A., Lingard, R., Ladwig, J., Hayes, D. \& Mills, M. (1999). Productive pedagogies. Brisbane, QLD: University of Queensland.

Martinek, T. \& Hellison, D. (1998). Values and goal-setting for underserved youth. Journal of Physical Education, Recreation and Dance, 69(7), 47-52.

Moodie, R., \& Hulme, A. (Eds.). (2004). Hands on bealth promotion. Melbourne, VIC: IP Communications.

National Health \& Medical Research Council. (1996). Health-promoting sport, arts and racing settings. Canberra, ACT: Commonwealth of Australia.

Olsen, M., Rynne, S., \& Macdonald, D. (2002). Gumala miruwarni: Meeting the needs of Aboriginal and Torres Strait Islander students in health and physical education. ACHPER Healtby Lifestyles Journal, 49(1), 11-15.

Queensland Government, Department of Communities. (2001). Cape York justice study. Retrieved 28 March, 2004, from www.mcmc.qld.govau.

Queensland Government. (2003). Meeting challenges making choices. Retrieved 19 0ctober, 2004, from http://www.mcmc.qld.gov.au/community/.

Queensland Health Newsletter. (2004). OTMHC Mental Health Projects. Retrieved 16 April, 2004, from wwwhealth.gld.govau/pahospital/qthmc/projects.asp. Queensland School Curriculum Council (QSCC). (2001). Position paper: Lifeskills. Brisbane: The State of Queensland, QSCC.

Shilton, T. R., \& Brown, W. (2004). Physical activity among Aboriginal and Torres Strait Islander people and communities. Joumal of Science and Medicine in Sport, Pbysical Activity Supplement, 7(1), 39-42.
Spradley, J. P. (1979). The ethnographic interview. New York, NY: Holt, Rinehart And Winston.

Tatz, C. (1995). Obstacle race: Aborigines in sport. Sydney, NSW: University of New South Wales Press.

Timperio, A., Salmon, J., \& Ball, K. (2004). Evidence-based strategies to promote physical activity among children, adolescents and young adults: Review and update. Journal of Science and Medicine in Sport, Physical Activity Supplement, 7(1), 20-29

University of Melbourne. (2003). Media release 981. Accessed 28 August, 2004, from http://uninews/unimeib.edu.au/articleid_981.html.

University of Melbourne. (2004). Media release 1446. Accessed 28 August, 2004, from http://uninews/unimelb.edu.au/articleid_981.html.

Walker, R., \& Oxenham, D. (2001). A sporting chance: An evaluation of the Rio Tinto AFL Kickstart Program in the Kimberley region. Perth, WA: Curtin Indigenous Research Centre, Curtin University of Technology.

World Health Organisation (WHO). (1993). Life skills education in schools. Geneva: WHO.

World Health Organisation (WHO). (1998). Healtb promotion glossary. Geneva: WHO.

World Health Organisation (WHO). (2003). Health and development through physical activity and sport. Geneva: WHO.

Wright, R. (1999). Skin taunts: Race discrimination in Australian rules football. Arena Magazine, August, 18.

\section{About the authors}

Dr Maree DinanThompson is a Senior Lecturer in the School of Education, James Cook University. Maree's research interests include Health and Physical Education curriculum, teacher agency and change, and more recently, physical activity and Indigenous youth.

Juanita Sellwood is an Indigenous Lecturer in the School of Education, James Cook University. Juanita's research interests include Indigenising Education with an investigation of Torres Strait Islander perspectives, recruiting and retaining Indigenous students in teacher education, and teachers and cultural diversity.

Felicity Carless is a Senior Project Officer in the Health Promotion Unit, Tropical Population Health Cairns Network. Felicity has collaborated with several agencies in Cairns and Cape York to undertake health promotion studies. 